5

6

7

\section{A METHOD FOR EVALUATING \\ THE MECHANICAL PERFORM ANCE \\ OF THIN-WALLED TITANIUM TUBES}

P.M. MacKenzie, C.A. Walker, J. McKelvie

Department of Mechanical Engineering, University of Strathclyde, Glasgow G1 1XJ, Scotland, UK.

peter.mackenzie@strath.ac.uk

Tel: 01415482045

Fax: 01415525105 


\section{ABSTRACT}

20 A method which was developed to compare the stress-strain properties of three types of

21 thin-walled, commercially pure titanium tubes is presented. The tubes were of types

22 intended for use in large heat-exchanger applications and were to be subjected to

23 significant plastic deformation during subsequent assembly processes. It had been

24 anticipated that small differences in chemical composition and tube-drawing treatment

25 would produce quite different characteristics. It is known that the properties of titanium

26 can exhibit considerable degrees of anisotropy, especially for wrought products;

27 although axial properties of the materials could be evaluated using standard test

28 equipment and procedures, a novel testing system had to be designed to allow the

29 circumferential properties to be assessed. Signific ant differences between tube types

30 were observed and anisotropic material behaviour was apparent.

31

32 Keywords:- anisotropic; commercially pure titanium; ductility; mechanical testing;

33 hydraulic; tubes. 


\section{INTRODUCTION}

35 Titanium and its alloys have desirable blends of properties such as low density, high

36 strength and high stiffness, each of which makes them attractive for many structural

37 applications. Coupled to these benefits are exceptional levels of resistance to corrosion

38 and oxidation and, compared with aluminium alloys, distinctly better creep-resistance.

39 For these reasons, the use of titanium and its alloys can be justified economically in an

40 increasing range of high-integrity areas, from aerospace to petrochemicals (and not

41 forgetting to mention the growing market in sports goods).

42

43 Approximately $25 \%$ of the market for metallic titanium is made up of the commercially

44 pure (CP) form. CP titanium is, in effect, an alloy of titanium, oxygen and traces of

45 several other elements. Although, in all of the various varieties which come under the

$46 \mathrm{CP}$ designation, metallic titanium makes up in excess of $99 \%$ of the content, the small

47 fractions of other elements which may be included can influence the mechanical

48 properties to a very significant degree. Most notably, small, controlled amounts of

49 oxygen are dissolved in solid solution to produce increases in strength but, ultimately,

50 with a significant reduction in ductility. CP titanium generally displays good ductility

51 and can be forged, rolled, drawn or extruded quite straightforwardly but its hexagonal

52 close packed ( $\alpha$-phase) structure does limit formability. In addition, the textures

53 developed in wrought products for $\alpha$ - titanium and its alloys can have a marked effect

54 on the mechanical properties of the finished material and distinctly anisotropic material

55 behaviour can be a common feature [1 - 6]. 
57 The work presented here was focussed on evaluating mechanical properties of thin-

58 walled CP titanium tubes intended for use in heat exchangers. The key justification of

59 the work was that, during the fabrication process, expansion of tubes in to tube-sheets

60 produces high levels of plastic deformation of the tube material circumferentially $[\mathbf{7 , 8}]$

61 and, to this end in particular, a novel method for as sessing the response of the material

62 in the circumferential direction was required.

\section{SPECIMEN MATERIALS}

65 Specimens of three different types of drawn tube were used in the investigation. Details

66 of oxygen content together with tube dimensions are summarised in Table 1.

Figure 1 contain s representative micrographs of the grain structure of each of the three

69 specimen groups, designated Types 'A', 'B' and 'C'. Type 'A', the only vacuum

70 annealed sample, shows very much larger grain diameter (by a factor of 4 to 5

71 approximately [9]) than do either of the other types. The three dimensional nature of the

72 texture could not be as sessed by optical microscopy alone and was beyond the scope of

73 the present work.

\section{AXIAL AND CIRCUMFERENTIAL LOADING CONFIGURATIONS}

Axial testing of the tubes was performed in a relatively straightforward manner, as

77 prescribed in [10], the British Standard. This requires quite simply that the tube ends,

78 through which loads were to be applied, be reinforced in a prescribed manner; it also

79 places requirements on the rate of loading and the method of recording results (these are 
discussed below). Specimen tube lengths of $400 \mathrm{~mm}$ satisfied the requirement of the

81 standard test. Loads were applied using an Instron 1342 servo-hydraulic test machine.

82

83 By contrast, an entirely novel setup had to be designed in order to enable circumferential loading of the material, with axial stresses, up to yield point at least, eliminated as far as possible; there is no published prior art with regard to th is.. Whilst there is a wealth of literature relating to the contiguous technology of hydroforming, for example, [11 - 14], this almost invariably deals with the application of intentional biaxial loading conditions. Indeed, [13] describes a method of testing tubular specimens with deliberately induced biaxial loads, so as to simulate the conditions found in the hydroforming process. The hydrau lic test rig constructed for the present purpose is shown schematically in Figure 2. It was designed to perform two main functions: to ensure loading of the specimens in the desired manner, i.e., no, or minimal, axial loading up to yield; and to enable controlled application of the loading or expansion,

94 this being achieved by having the Instron test mach ine previously mentioned adapted to

95 provide the driving force for the rig. As shown in Figure 3, the test rig was mounted

96 between the platens of the test machine, thereby enabling full feedback control of the

97 pressure applied to the specimens.

\section{SPECIMEN SEALING ARRANGEMENTS}

100 The test rig also incorporated the specimen holder consisting of a removable steel core,

101 with seals, mounted between a crosshead and the pump body. Specimens of dimensions

102 given in Figure 4 were mounted on the core, and through this, the pressurised hydraulic 103 oil was delivered. 
105 Initially, it had been intended that the specimen sealing arrangement would consist of a

106 bespoke nitrile rubber bladder but this proved to be unsatisfactory. From axial test

107 results, it had appeared that pressures of approximately $100 \mathrm{MPa}$ might be required in

108 order to take the tubes to failure. This system was capable of containing only $10 \%$ of the

109 target value. Bonding the seal to the central core using cyanoacrylate adhesive produced

110 a substantial improvement in performance but, at seal failure pressures of about 60

$111 \mathrm{MPa}$, this still fell short of the programme requirement.

112

113 In order to minimise axial loads up to yield, it was es sential that the tubes be free-

114 floating, i.e., the ends could not be plugged during the tests. To this end, an alternative

115 technology to the bladder seal proved to be entirely satisfactory. This consisted of a

116 setup using conventional nitrile rubber 'O'-ring seals on a special core, in tandem with

117 spiral PTFE backing washers to prevent seal extrusion (Figure 5). Steel rings of

118 thickness $2 \mathrm{~mm}$ and diameter $0.2 \mathrm{~mm}$ greater than those of the specimens were used to

119 support the specimen at the point of contact with the 'O'-rings. This setup allowed

120 pressures up to $140 \mathrm{MPa}$ to be contained.

121

122 A key feature of the design is that the pressure end-loads imparted through the specimen

123 cores were supported by, on the one hand, the pump body, and on the other, by the

124 retaining cross-head mounted on reaction columns. By using two-piece cores, a

125 potential problem in the oil-way at the core to body seal was eliminated since it was

126 possible, by selecting appropriate dimensions, to ensure that the outward hydraulic force 
127 tending to open the seal was always more than balanced by the pressure force on the

128 core from within the specimen.

129

130 Prior to each test, the hydraulic system, including the fresh specimen, was recharged

131 with working fluid (Esso Nuto-H46) by first evacuating it to ensure no air pockets

132 remained.

133

134 TEST PROCEDURE

135 Instrumentation comprised: Instron $100 \mathrm{kN}$ load cell (for the axial loading

136 configuration); Shape $140 \mathrm{MPa}$ pressure transmitter (for the circumferential loading

137 configuration); a purpose-built clip-gauge diametrical strain transducer, Figure 6,

138 essentially, two spring steel blades to which were attached four $6.35 \mathrm{~mm} 1000 \Omega$ strain

139 gauges connected in full-bridge configuration; $6.35 \mathrm{~mm} 120 \Omega$ strain gauges for

140 attachment directly to the specimens; signal conditioning electronics; autographic

141 recording equipment.

142

143 The specimen strain gauges were used during the hydraulic tests to monitor more

144 precisely the behaviour up to yield, the diametrical transducer being intended for

145 measurement of gross strains only. The diametrical transducer was calibrated and

146 checked for linearity using precision ground cylindrical gauge bars; in practice, it was

147 found invariably to give readings within $0.5 \%$ of micrometer measurements of the

148 specimen diameters at failure.

149 
150 In evaluating the axially loaded properties of the tubes, a conventional setup was used.

151 The loads were obtained from the test machine load cell and displacements to yield

152 whilst a $50 \mathrm{~mm}$ gauge-length LVDT displacement transducer provided measurements of

153 extension. Elongation at failure was measured using pre-marked scales on the

154 specimens over an initial gauge-length of $50 \mathrm{~mm}$.

155

156 Strain rates for both loading configurations were set to be in the range 50 to 120

157 microstrain per second up to the $0.2 \%$ proof stress level, followed by an increase in rate

158 to give failure within one add itional minute.

159

160 Figure 7 shows representative traces, taken from the circumferential loading tes ts, of

161 internal pressure v. diametrical strain records for each of the three sample types.

162

\section{RESULTS AND DISCUSSION}

164 The results are summarised in Table 2, and in Figure 8. For the axial loading

165 configuration, the values given are for en gineering stress-strain and similarly for the

166 circumferentially loaded case, except that here, instead of the tensile strength being

167 given, the circumferential stress component at failure has been presented; this was

168 calculated using the recorded internal pressure, $P_{f}$, and the final maximum internal

169 radius, $r_{f}$, at failure, to obtain the applied circumferential stress thus:

$$
\sigma_{h}=\frac{P_{f} r_{f}}{t}
$$

171 The tensile strength for the axial case was taken, conventionally, to be the engineering

172 stress taken from the maximum point on the load-displacement curve. The distinct yield 
173 point for the Type 'C' record shown in Figure 7 was, to a varying degree, apparent for

174 all Type 'C' specimens tested.

175

176 There are some areas to be careful of in examining the se data. First of all, whilst it is

177 reasonable to use the results for axial elongation at failure to compare the performance

178 of the different tube types, and to use, similarly, the diametrical strain results, to make

179 direct comparison between the axial and diametrical strain performance would be

180 unsound. The failure by necking in the axial-loading case produces a very different

181 plastic flow regime from that observed in the circumferentially loaded tests.

182 Furthermore, the gross changes in tube geometry observed in the circumferential

183 loading tests progressively introduced an increasingly significant axial component of

184 stress. In other words, the performance one is able to observe here is influenced by the

185 specimen geometry at high strain levels; the test should be regarded as a method for

186 assessing the material-component combination, not as a proposed standard material test

187 per se. For hydraulic loading in the setup developed here, and by measuring the change

188 in in ternal radius from the initial condition, $r_{l}$, to any strained (bulged) condition of

189 radius, $r_{2}$, one can evaluate the magnitude of the axial hydraulic force. From this, the

190 ratio of applied stress components is given by equation (2):

$$
\frac{\sigma_{A X I A L}}{\sigma_{H O O P}}=\frac{P\left(r_{2}^{2}-r_{1}^{2}\right)}{2 r_{2} t} \cdot \frac{t}{P r_{2}}
$$

$$
=0.5 \cdot\left(1-\left(\frac{r_{1}}{r_{2}}\right)^{2}\right)
$$

$$
=0.5 \cdot\left(1-\left(\frac{1}{1+\varepsilon_{d}}\right)^{2}\right)
$$


194 Thus, for the maximum value of diametrical strain, $\varepsilon_{d}$, observed during hydraulic

195 testing (69\%), an axial component of stress equal to $32 \%$ of the applied circumferential

196 stress would be induced. On the other hand, at the typical strain values (about $0.6 \%$ )

197 measured at the Proof Stress, the axial component of stress introduced due to the

198 bulging of the tubes can be shown to amount to much less than $1 \%$ of the applied

199 circumferential stress.

201 We can note certain other points with a considerable degree of confidence, however. It

202 is clear that, of the three batches, Type ' $\mathrm{B}$ ', with the lowest oxygen content, exhibited

203 the lowest Proof Stress, the lowest tensile strength, and the highest ductility for both

204 loading configurations. Type ' $\mathrm{C}$ ', having the highest oxygen content, also showed the

205 highest values for both axial tensile strength and for failure pressure in the hydraulic

206 tests, but with by far the greatest degree of scatter of the three tube types. Figure 9

207 shows two examples of circumferen tially loaded Type ' $C$ ' tubes post-failure; of the

208 thirteen specimens of this type, ten failed by pinhole leak and the remaining three by

209 unstable fracture. In the cases where fracture occurred, the diametrical strain at failure

210 was at the upper end of the range for this type (73\% to $77 \%$ for the three results,

211 compared to a mean of $63 \%$ ). All of the Type 'A' and Type 'B' specimens failed by

212 unstable fracture.

213

214 Given the negligible change in geometry observed at the yield point, one can reasonably

215 draw comparisons between the axial and circumferential values for Proof Stress: whilst

216 Types ' $\mathrm{B}$ ' and ' $\mathrm{C}$ ' showed increases of $31 \%$ and $25 \%$ respectively in the circumferential 
217 direction, Type 'A' the large-grained vacuum annealed batch, proved to be closer to

218 isotropic in this respect showing an increase of only $14 \%$.

219

220 In passing, it might be noted that the Hall-Petch relationship [15, 16] states that:

221

$$
\sigma_{y}=\sigma_{0}+\frac{K}{\sqrt{d}} \ldots \ldots \ldots \ldots \ldots \ldots
$$

222 where the yield stress, $\sigma_{\mathrm{y}}$, can be predicted as a function of: $\sigma_{0}$, the "intrinsic yield" of

223 the material; $d$, the grain diameter; and $K$, a material constant. In the present case,

224 although the three sets of specimens were of near identical chemical composition (and

225 within the range prescribed for "commercially pure"), a cursory inspection of the

226 micrographs in Figure 1 confirms that Type ' $\mathrm{B}$ ' has the smallest grain size and yet it

227 also has the lowest measured values of $\sigma_{y}$ for both axial and circumferential loading

228 cases. In other words, the observed results run counter to the relationship and it

229 therefore does not hold for this situation. This can be explained in that, as previously

230 stated, the mechanical properties of CP titanium are highly sensitive to very small

231 variations in chemical composition (of the scale seen here) and, furthermore, an

232 additional determining factor, the initial level of dislocation density in the materials was

233 “as manufactured", i.e., was not deliberately controlled for investigative purposes.

235 In summary, the primary objective of this work was to devise a system to enable

236 objective evaluation of, and comparison between, the properties to failure for tube

237 specimens of near-identical geometry and the results obtained from the test setup which

238 was developed have demonstrated its capability of performing this task satis factorily. 239 


\section{CONCLUSIONS}

241 A system for making comparative evaluations of, separately, the axially and

242 circumferentially loaded performance of tubular specimens of CP titanium has been

243 demonstrated. This required the development of a new experimental setup for applying

244 circumferential stresses hydraulically; using this, axial loads were essentially eliminated

245 up to specimen yield. The arrangement also enabled useful comparisons to be made of

246 ductility up to failure with circumferential loading predominant. Axial load testing

247 followed the prescribed method of a standard test procedure.

249 Tests were performed on three candidate tube types intended for a large-scale heat 250 exchanger application. Measured mechanical properties differed significantly between

251 the three types. All three batches displayed yield behaviour which to a significant

252 degree was dependent on orientation. Differences in performance between the tube 253 types could not be attributed directly to observed differences in average grain size. The

254 tests confirmed that tube Type ' $\mathrm{C}$ ', having the highest oxygen content, was, generally, 255 the strongest of the three groups over both loading regimes, but at little or no cost in 256 relation to its ductility; Type ' $\mathrm{C}$ ' was, therefore, deemed most appropriate for the 257 proposed high-integrity application.

259 Finally, the findings confirm that, where it is a requirement that detailed quantitative 260 comparison be made between types of CP titanium tube produced by different

261 manufacturing process, or having small differences in chemical composition, it is

262 important to conduct tests on specimens of finished tubes, there being no convenient 263 method available for reliably inferring mechanical properties otherwise. 


\section{REFERENCES}

1) Titanium Information Group, Titanium for Marine and Offshore Applications - A Designers' and Users' Handbook. Kjeller, Norway: Institutt for Energiteknikk, 1999.

2) Seagle, S.R., The state of the USA titanium industry in 1995. Materials Science and Engineering 1996; A213, 1-7.

3) Yamada, M., An overview on the development of titanium alloys for non-aerospace application in Japan, Materials Science and Engineering 1996; A213, 8-15.

4) Jaffee, R.I., Promisel, NE., (eds), The Science, Technology and Application of Titanium. Oxford, UK: Pergamon Press, 1970.

5) Bache, M.R., Evans, W.J., Suddell, B., Herrouin, F.R.M., The effects of texture in titanium alloys for engineering components under fatigue, International Journal of Fatigue 2001;23, S153 - S159.

6) Davies, R.W., Khaleel, M.A., Kinsel, W.C., Zbib, H.M. (2002) Anisotropic yield locus evolution during cold pilgering of titanium alloy tubing, Trans ASME, Journal of Engineering Materials and Technology 2002; 124, 125 - 134.

7) Goodier, J.N., Schoessow, G.J., The holding power and hydraulic tightness of expanded tube joints: analysis of the stress and deformation, Trans ASME 1943; 65, 489-96.

8) Alexander, J.M, Ford, H., On Expanding a Hole from Zero Radius in a Thin Infinite Plate, Proceedings of the Royal Society of London. Series A, Mathematical and Physical Sciences 1954;226, 543-561.

9) ASTM, Standard test methods for determining average grain size, E112-96, 1996.

10) BS EN 10002 - 1:2001, Metallic materials - tensile testing, British Standards 
Institute, 2001.

11) Tirosh, J., Neuberger, A., Shirizly, A., On tube expansion by internal fluid pressure with additional compressive stress, International Journal of Mechanical Science $1996 ; 38,839-851$.

12) Zhang, S.H., Developments in hydroforming, Journal of Materials Processing Technology 1999; 91, 236-244.

13) Sokolowski, T., Gerke, K., Ahmetoglu, M., Altan, T., Evaluation of tube formability and material characteristics: hydraulic bulge testing of tubes, Journal of Materials Processing Technology 2000; 98, 34-40.

14) Lang, L.H., Wang, Z.R., Kang, D.C., Yuan, S.J., Zhang, S.H., Danckert, J., Nielsen, K.B., Hydroforming highlights: sheet hydroforming and tube hydroforming, Journal of Materials Processing Technology 2004; 151, 165-177

15) Polmear, I.J. (1989) Light Alloys. London, UK: Edward Arnold, 1989.

16) Kao, Y.L., Tu, G.C., Huang, C.A., Liu, T.T., A study on the hardness variation of $\alpha$ - and $\beta$-pure titanium with different grain sizes, Materials Science and Engineering 2005; A 398, 93-98. 


\section{FIGURES AND CAPTIONS}

FIGURE 1: Micrographs of Type 'A', 'B' and 'C' commercially pure titanium tube specimens.

FIGURE 2: Schematic of self-contained high-pressure pump and specimen holder.

FIGURE 3: Pump and specimen holder mounted in jaws of servo-hydraulic test machine.

FIGURE 4: Specimen dimensions.

FIGURE 5: Test-rig core and specimen sealing arrangement incorporating nitrile ' $O$ 'rings and PTFE spiral backing washers to prevent seal extrusion.

FIGURE 6: Clip gauge diametrical strain transducer (dimensions in mm). $1000 \Omega$ strain gauges were positioned at 'SG'. The tube diameters were measure between the $38 \mathrm{~mm}$ radius arcs of a pair of jaws attached to the blade ends.

FIGURE 7: Sample records of applied internal pressure v. diametrical strain from circumferential loading tests.

FIGURE 7: Summary of results of tests to failure

FIGURE 8: Examples of post-failure Type 'C' specimens - unstable fracture and "pinhole" failure. 
Click here to download high resolution image
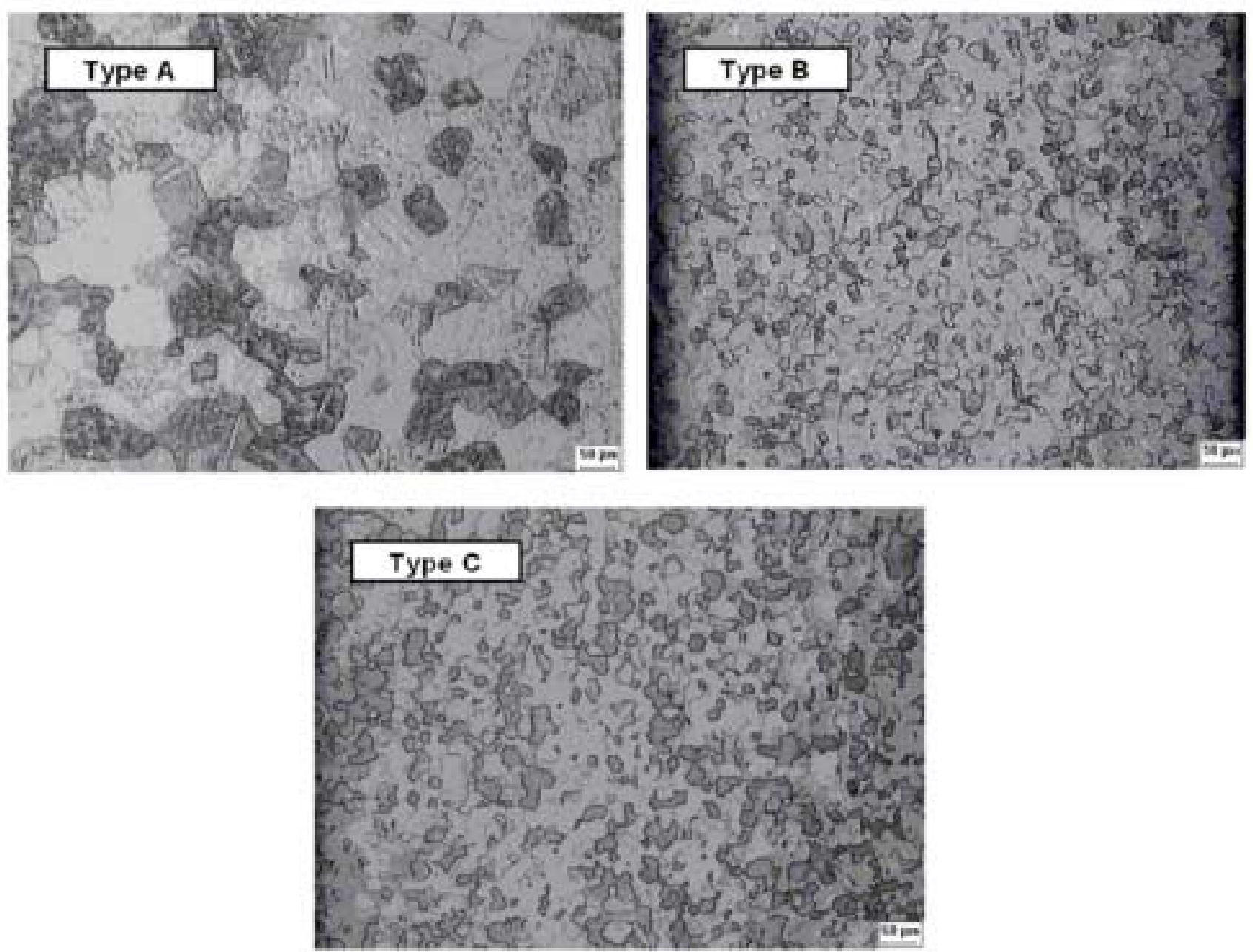


\section{Figure2}

Click here to download high resolution image

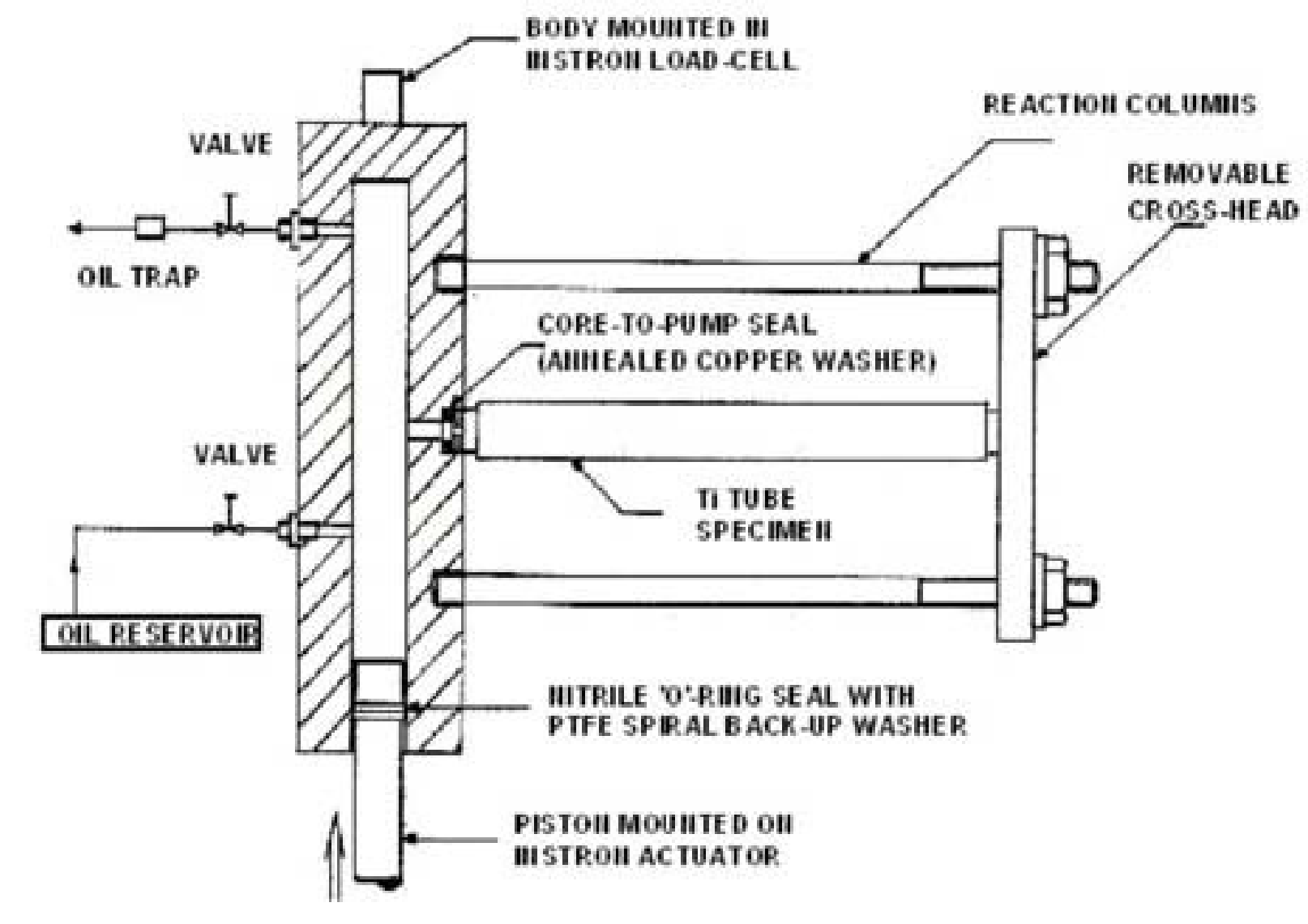

BODY MOUITED III 
Click here to download high resolution image

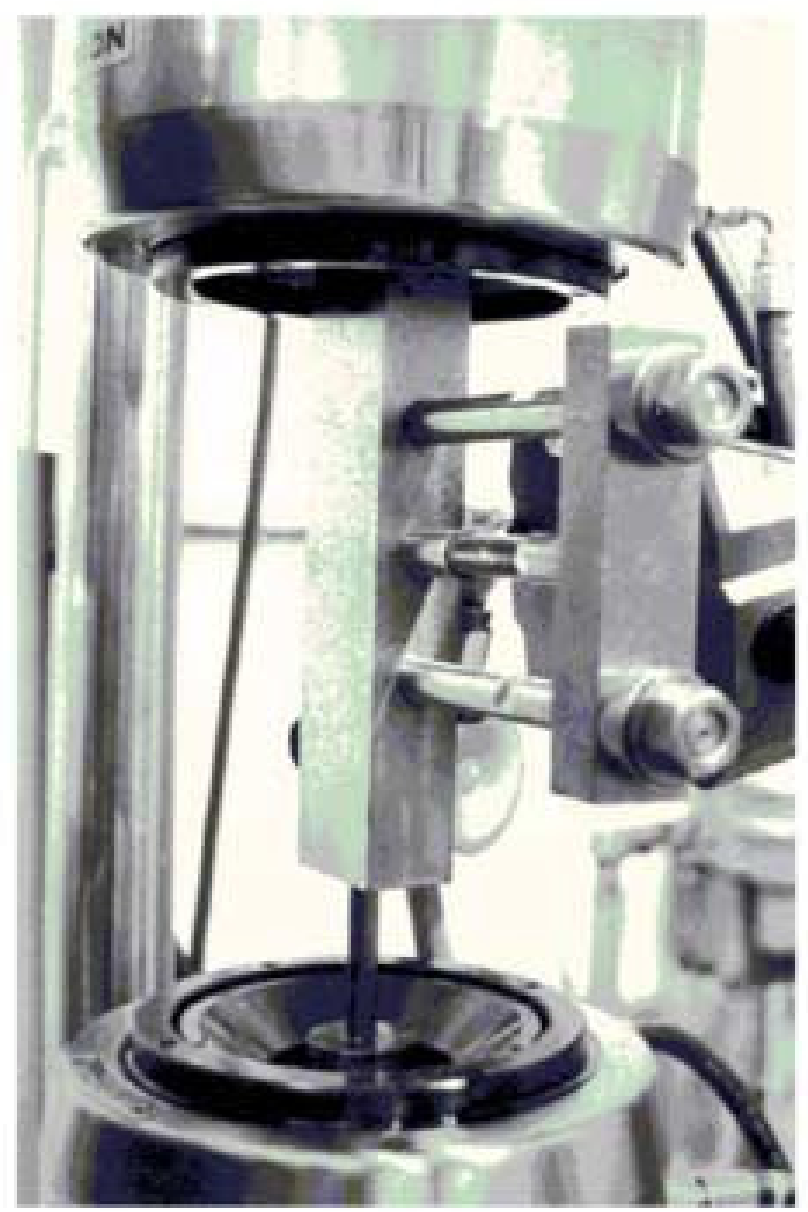


Click here to download high resolution image

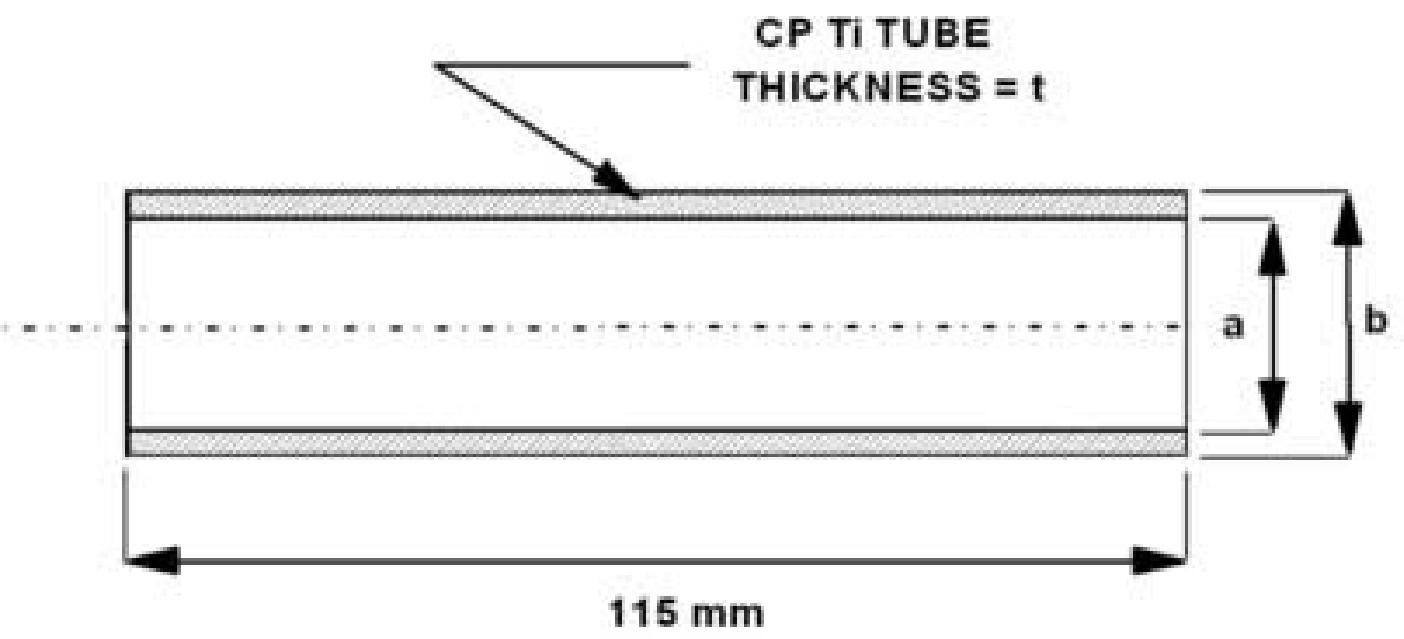


Click here to download high resolution image
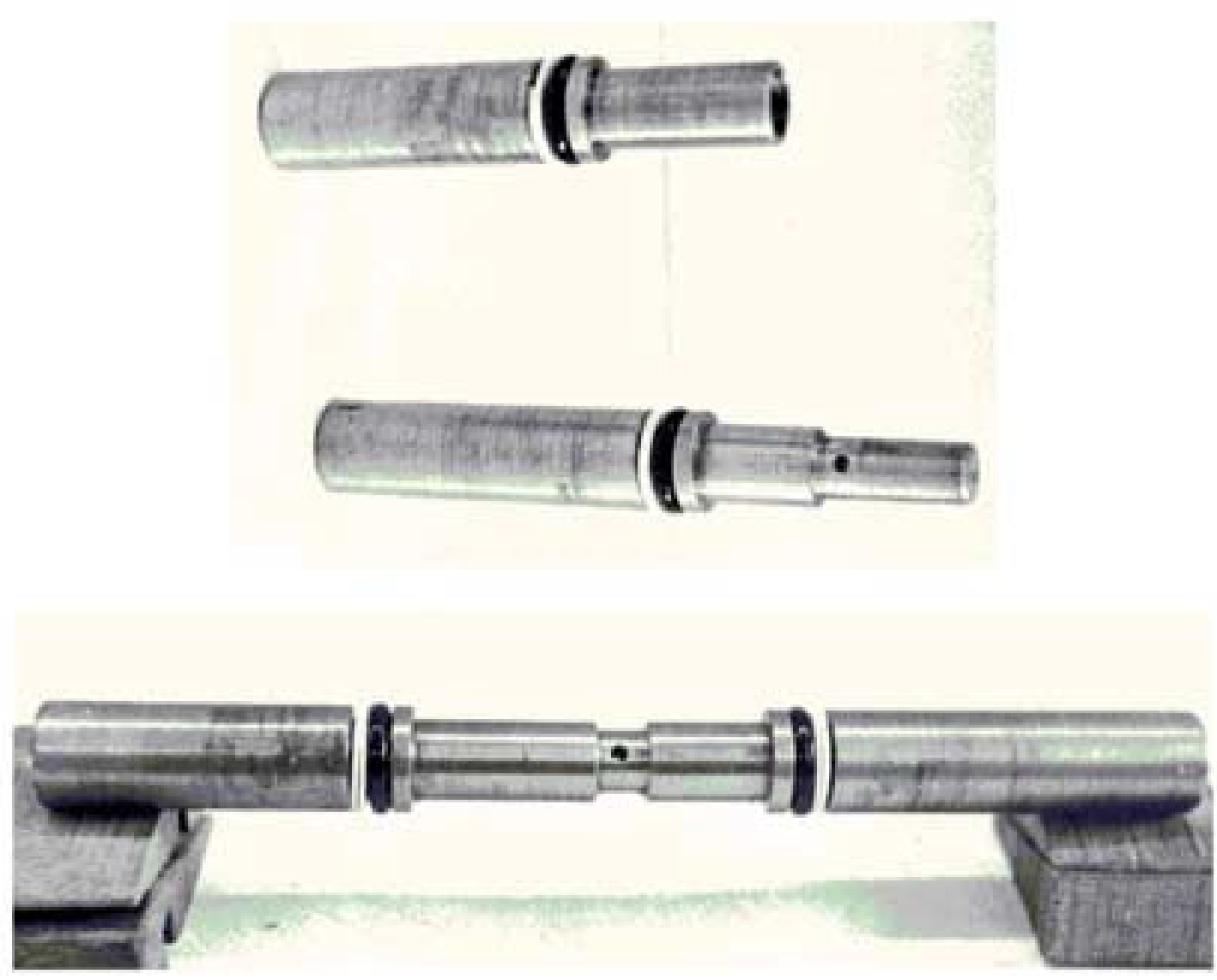
Figure6

Click here to download high resolution image

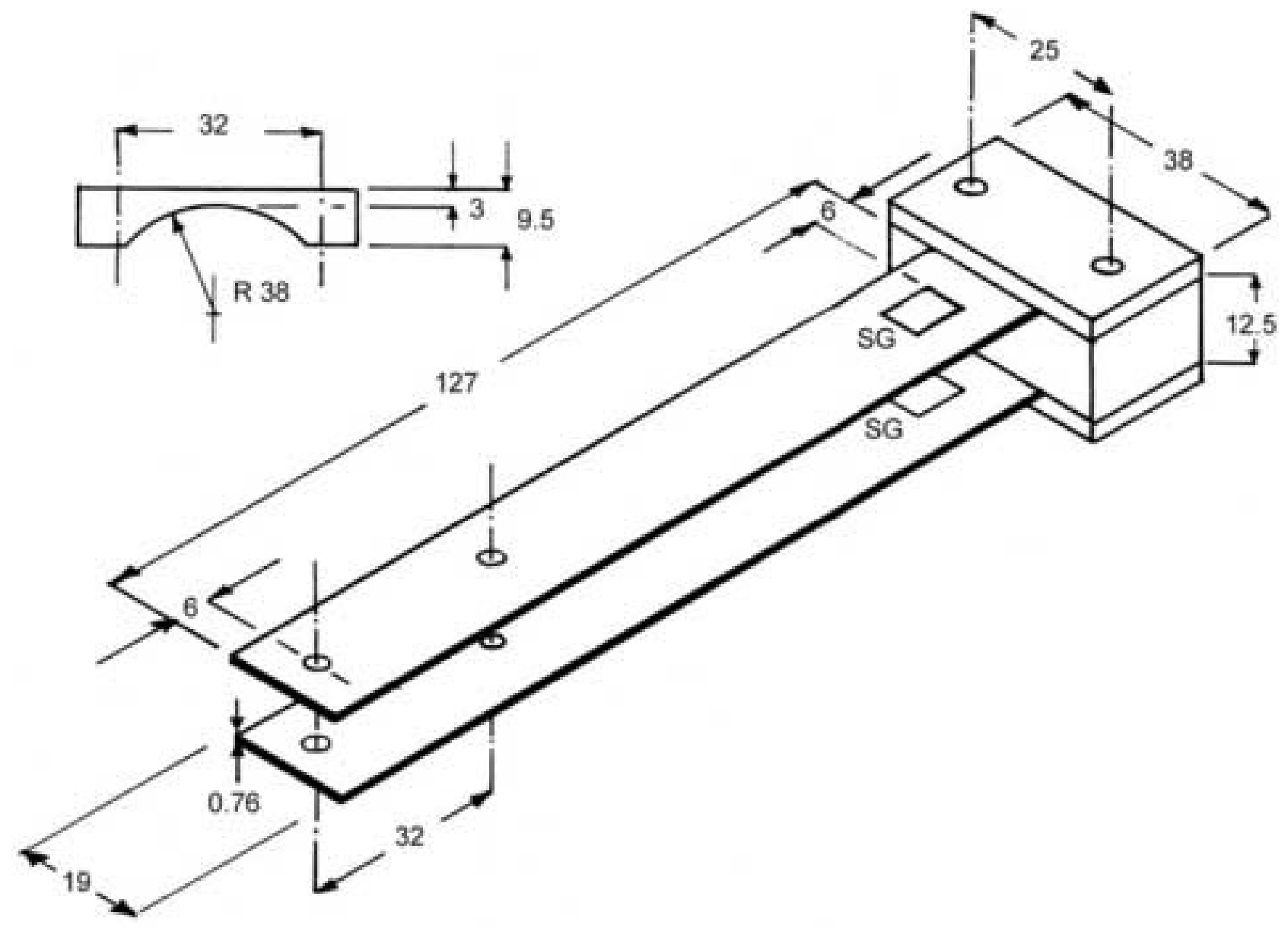




\section{Figure7}

Click here to download high resolution image

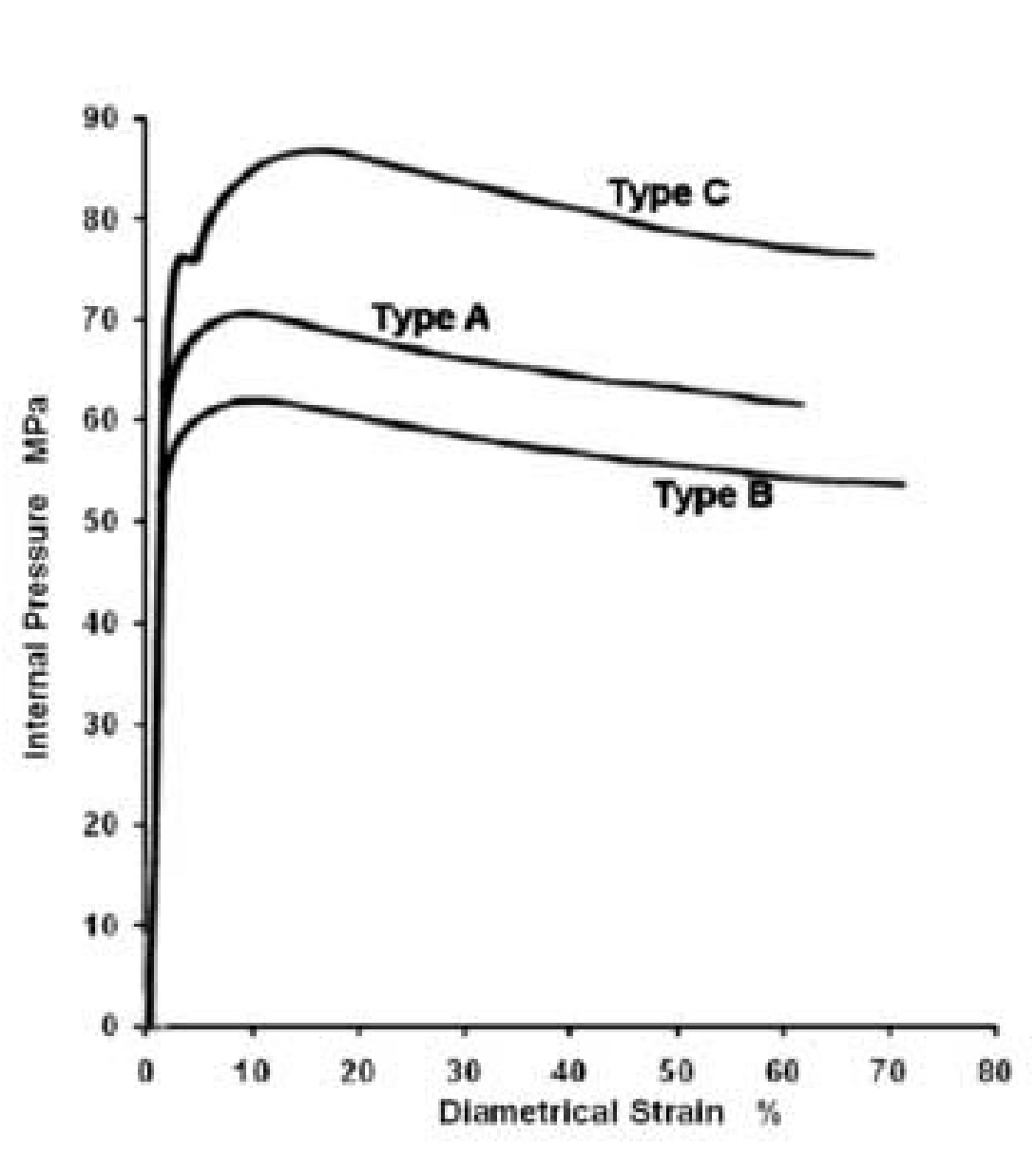


Click here to download high resolution image
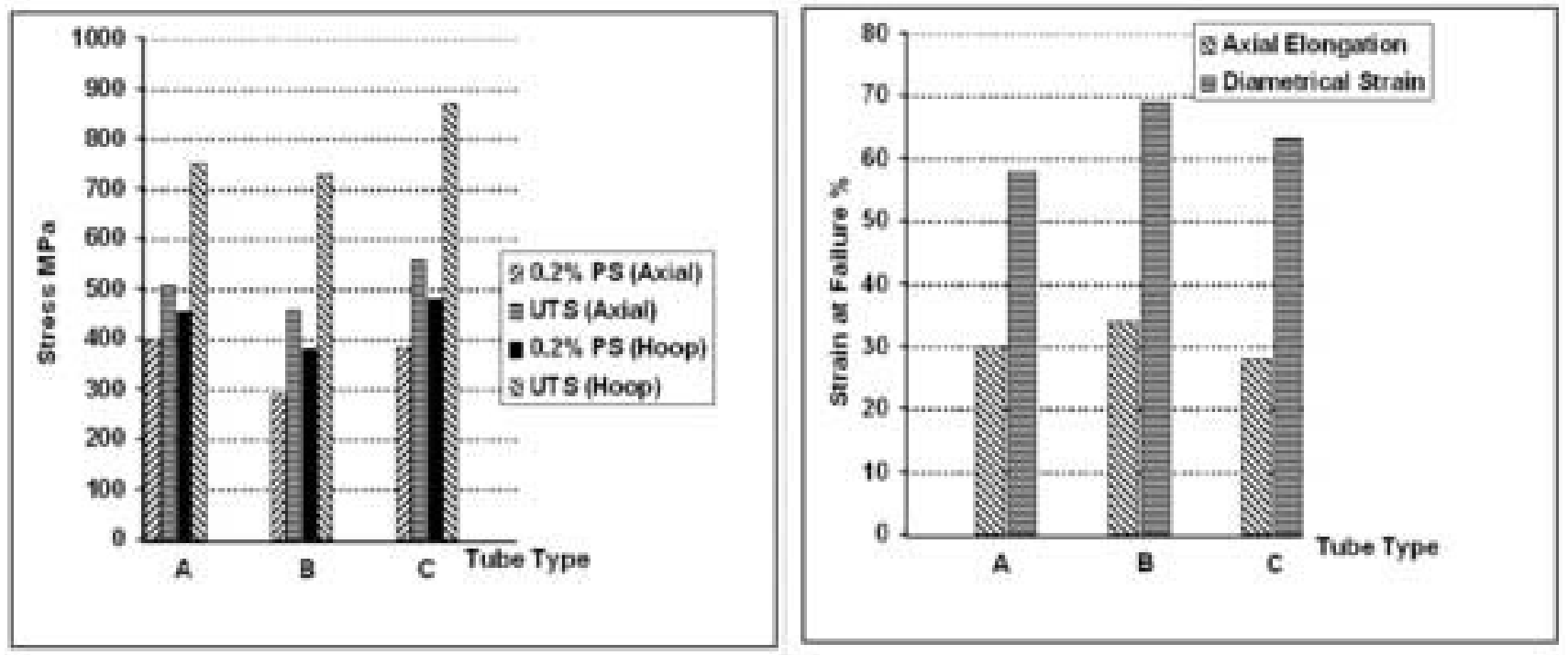
Click here to download high resolution image

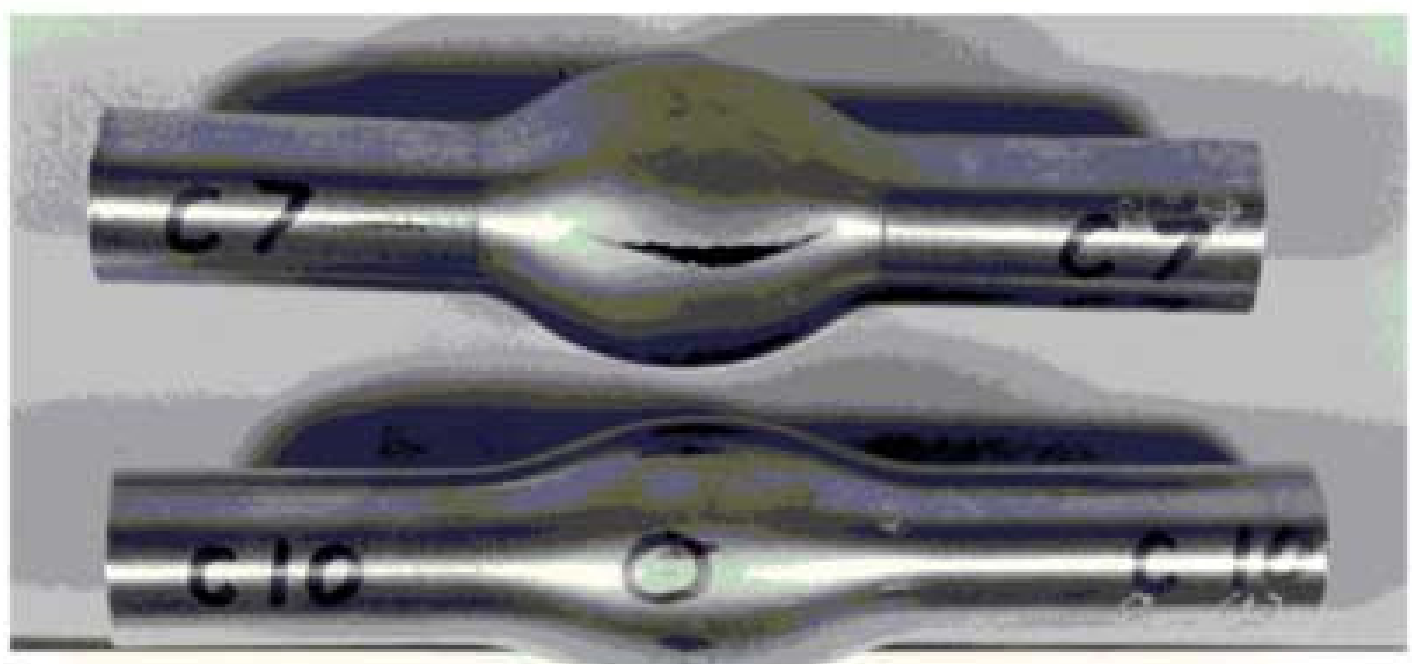


TABLE 1

Description of specimen tube types.

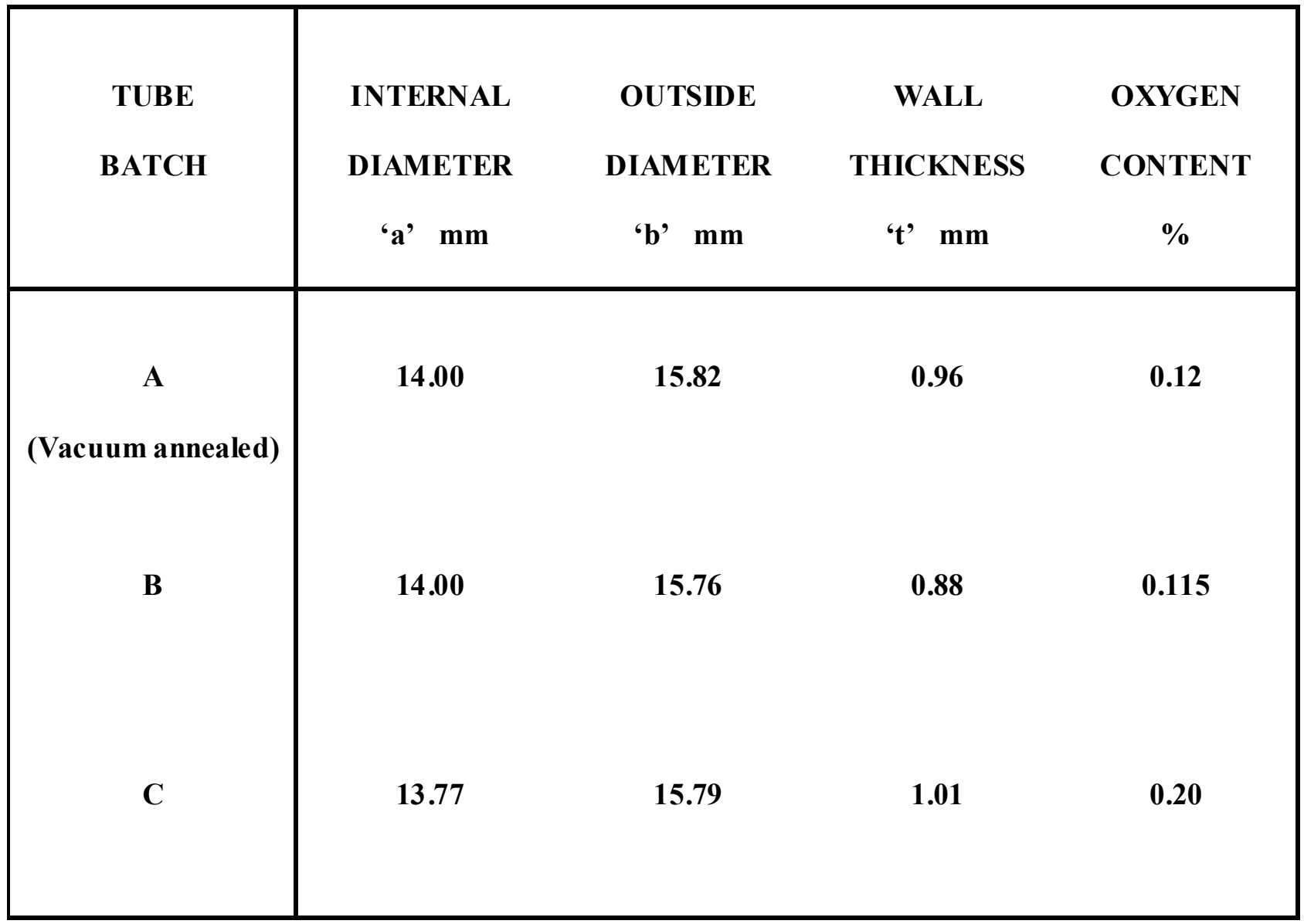


TABLE 2

Summary of results for tensile and circumferential loading tests (standard deviation in brackets).

\begin{tabular}{|c|c|c|c|c|c|c|}
\hline \multirow[b]{2}{*}{ TUBE BATCH } & \multicolumn{3}{|c|}{ AXIAL LOADING CONFIGURATION } & \multicolumn{3}{|c|}{ CIRCUMFERENTIAL LOADING CONFIGURATION } \\
\hline & $\begin{array}{c}0.2 \% \text { PROOF } \\
\text { STRESS } \\
\text { MPa }\end{array}$ & $\begin{array}{c}\text { TENSILE } \\
\text { STRENGTH } \\
\text { MPa }\end{array}$ & $\begin{array}{c}\text { ELONGATION } \\
\\
\%\end{array}$ & $\begin{array}{c}0.2 \% \text { PROOF } \\
\text { STRESS } \\
\text { MPa }\end{array}$ & $\begin{array}{c}\text { CIRCUMFERENTIAL } \\
\text { COMPONENT OF } \\
\text { STRESS AT FAILURE } \\
\text { MPa }\end{array}$ & $\begin{array}{c}\text { DIAMETRICAL } \\
\text { STRAIN } \\
\%\end{array}$ \\
\hline $\mathbf{A}$ & $\begin{array}{r}400 \\
(1.8)\end{array}$ & $\begin{array}{l}506 \\
(5.1)\end{array}$ & $\begin{array}{c}30 \\
(1.2)\end{array}$ & $\begin{array}{l}454 \\
(1.5)\end{array}$ & $\begin{array}{r}748 \\
(7.0)\end{array}$ & $\begin{array}{c}58 \\
(1.5)\end{array}$ \\
\hline B & $\begin{array}{l}289 \\
(3.5)\end{array}$ & $\begin{array}{l}455 \\
(3.3)\end{array}$ & $\begin{array}{c}34 \\
(1.7)\end{array}$ & $\begin{array}{l}379 \\
(6.9)\end{array}$ & $\begin{array}{c}727 \\
(2.9)\end{array}$ & $\begin{array}{c}69 \\
(1.2)\end{array}$ \\
\hline $\mathbf{C}$ & $\begin{array}{l}383 \\
(3.2)\end{array}$ & $\begin{array}{c}559 \\
(9.8)\end{array}$ & $\begin{array}{c}28 \\
(2.2)\end{array}$ & $\begin{array}{r}478 \\
(4.9)\end{array}$ & $\begin{array}{c}870 \\
(45.4)\end{array}$ & $\begin{array}{c}63 \\
(10.5)\end{array}$ \\
\hline
\end{tabular}

